\title{
Letter to the Editor Regarding "Influence of Baseline Physical Activity as a Modifying Factor on COVID-19 Mortality: A Single-Center, Retrospective Study"
}

\author{
Charles Phillipe de Lucena Alves (D) - Marcelo Rodrigues dos Santos (D) • \\ Daisy Motta-Santos (iD
}

Received: April 5, 2021 / Accepted: January 21, 2022 / Published online: February 4, 2022

(c) The Author(s) 2022

Keywords: COVID-19; Physical activity; Mortality and exercise

Dear Editor,

We congratulate Salgado-Aranda et al. on their paper "Influence of Baseline Physical Activity as a Modifying Factor on COVID-19 Mortality: A Single-Center, Retrospective Study", which discusses the possible influence of baseline physical activity level on COVID-19 mortality [1]. We endorse regular physical activity for a healthy lifestyle, but some data and interpretation included in this paper can be misleading.

The authors conclude on the basis of a retrospective and observational study that sedentary behavior increases the mortality of hospitalized patients with COVID-19 (13.8\%

C. P. de Lucena Alves $(\bowtie)$

Postgraduate Program in Epidemiology, Federal University of Pelotas, R. Mal Deodoro, 1160-Centro, Pelotas, RS 96020-220, Brazil

e-mail: charleslucenaa@gmail.com

M. R. dos Santos

Instituto do Coração (InCor), Hospital das Clínicas HCFMUSP, Faculdade de Medicina, Universidade de São Paulo, São Paulo, SP, Brazil

D. Motta-Santos

Sports Department of the School of Physical Education, Physiotherapy and Occupational Therapy (EEFFTO) of the Federal University of Minas Gerais (UFMG), Belo Horizonte, Brazil and $1.8 \%$ for sedentary and active group, respectively). However, there are many problems that may hinder these conclusions. The data presented by the authors do not support these conclusions mentioned in the abstract and in the full text, and this characterizes "spin" or misleading reports [2]. Additionally, the authors also gave some recommendations for clinical practice based on an observational study [3]. It is important to highlight that recommendations from observational (and retrospective) studies can be unfortunately flawed for clinical practice.

Therefore, some points need to be emphasized. First, the physical activity level was measured using the Rapid Assessment of Physical Activity Scale (RAPA) questionnaire, where patients self-reported their previous physical activity data by telephone. However, as described by the authors, in the case of patients who died (45 subjects), the questionnaire was filled out by a family member. Obviously, this is not the best method and it is important to provide more details about these patients and RAPA data. In this case, family members probably did not know about the patient's level of physical activity. Self-reported physical activity level questionnaires have a memory bias, which may make it impossible to conclude the outcome of the study. It seems that if a family member answers the questions, bias may be even greater. Additionally, there was no mention about 
RAPA 2, which provides valuable information on the type of physical exercise performed. Why did the authors not include this information? There is no mention about criteria defining physical activity habits.

This is relevant information considering that the last physical exercise bout could affect the prognosis of a hospitalized patient. As well, we have some studies suggesting that lockdown can affect physical activity levels. Additionally, the way you measure physical activity can have different impacts, such as different follow-up, amount of physical activity measures, and measurement methods (by accelerometer or questionnaires) [4].

In the baseline data (Table 1), age and the prevalence of comorbidities between the sedentary (group 1) and active group (group 2) are different for some chronic diseases. This imbalance between groups makes the conclusion of the study inappropriate. In a sense, to the best of our knowledge, sicker patients can impact reverse causality problems. For example, did the patients die as a result of COVID-19 complications due to being sick at the baseline or owing to sedentary lifestyle? It is necessary to have a control for pre-existing diseases at baseline or exclude patients with chronic diseases (e.g., hypertension, diabetes mellitus, and dyslipidemia) at baseline [5].

The study was not clear about the primary outcome. The sample size calculation is missing and unfortunately the study has no statistical power. We recalculated the sample size for this study considering alpha of 0.05 , beta of $95 \%$, a $50 \%$ proportion of exposed and unexposed subjects, and a relative hazard of $20 \%$. The total number of subjects needed to achieve the number of events is 1104 (552 for each group) with a total number of events needed of 462 . Moreover, multivariate Cox regression analysis was not adjusted for several comorbidities such as male, hypertension, pulmonary disease, heart disease, cerebrovascular disease, and liver disease. With only four deaths in the active group and with a short follow-up it is hard to conclude that sedentary lifestyle has an HR of 5.91 (1.80-19.41). This huge confidence interval shows that the study has several methodological issues to be discussed.
Finally, we appreciate the opportunity to read this paper. However, we would like these points to be considered in order to improve transparency and scientific integrity.

\section{ACKNOWLEDGEMENTS}

Funding. No funding or sponsorship was received for this study or publication of this article.

Authorship. All named authors meet the International Committee of Medical Journal Editors (ICMJE) criteria for authorship for this article, take responsibility for the integrity of the work as a whole, and have given their approval for this version to be published.

Authorship Contributions. CPLA, MRS, and DMS: conceptualization and methodology; writing original draft preparation; writing, reviewing, and editing and final version approved.

Disclosures. Charles Phillipe de Lucena Alves, Marcelo Rodrigues dos Santos, and Daisy Motta-Santos have nothing to disclose.

Compliance with Ethics Guidelines. This article is based on previously conducted studies and does not contain any new studies with human participants or animals performed by any of the authors.

Open Access. This article is licensed under a Creative Commons Attribution-NonCommercial 4.0 International License, which permits any non-commercial use, sharing, adaptation, distribution and reproduction in any medium or format, as long as you give appropriate credit to the original author(s) and the source, provide a link to the Creative Commons licence, and indicate if changes were made. The images or other third party material in this article are included in the article's Creative Commons licence, unless indicated otherwise in a credit line to the material. If material is not included in the article's Creative Commons licence and 
your intended use is not permitted by statutory regulation or exceeds the permitted use, you will need to obtain permission directly from the copyright holder. To view a copy of this licence, visit http://creativecommons.org/licenses/by$\mathrm{nc} / 4.0 /$.

\section{REFERENCES}

1. Salgado-Aranda R, Pérez-Castellano N, Núñez-Gil I, et al. Influence of baseline physical activity as a modifying factor on COVID-19 mortality: a singlecenter, retrospective study. Infect Dis Ther. 2021. https://doi.org/10.1007/s40121-021-00418-6.

2. Yavchitz A, Ravaud P, Altman DG, et al. A new classification of spin in systematic reviews and metaanalyses was developed and ranked according to the severity. J Clin Epidemiol. 2016;75:56-65.
3. Prasad V, Jorgenson J, Ioannidis JPA, Cifu A. Observational studies often make clinical practice recommendations: an empirical evaluation of authors' attitudes. J Clin Epidemiol. 2013;66(4):361-366.e4.

4. Strain T, Wijndaele K, Sharp SJ, Dempsey PC, Wareham $\mathrm{N}$, Brage $\mathrm{S}$. Impact of follow-up time and analytical approaches to account for reverse causality on the association between physical activity and health outcomes in UK Biobank. Int J Epidemiol. 2020;49(1):162-72.

5. Rezende LFM, Lee DH, Ferrari G, Giovannucci E. Confounding due to pre-existing diseases in epidemiologic studies on sedentary behavior and all-cause mortality: a meta-epidemiologic study. Ann Epidemiol. 2020;52:7-14.

\section{Publisher's Note}

Springer Nature remains neutral with regard to jurisdictional claims in published maps and institutional affiliations. 